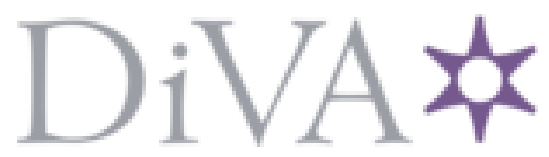

http://www.diva-portal.org

\title{
Postprint
}

This is the accepted version of a paper published in Entrepreneurship and Regional Development. This paper has been peer-reviewed but does not include the final publisher proof-corrections or journal pagination.

Citation for the original published paper (version of record):

Jansson, J. (2011)

Emerging (internet) industry and agglomeration: Internet entrepreneurs coping with uncertainty.

Entrepreneurship and Regional Development, 23(7-8): 499-521

http://dx.doi.org/10.1080/08985620903505987

Access to the published version may require subscription.

N.B. When citing this work, cite the original published paper.

Permanent link to this version:

http://urn.kb.se/resolve?urn=urn:nbn:se:uu:diva-161099 


\section{Emerging (internet) industry and agglomeration: internet entrepreneurs coping with uncertainty}

Johan Jansson

Full reference:

Jansson, J. (2011) "Emerging (internet) industry and agglomeration: coping with uncertainty". Entrepreneurship and Regional Development. Vol. 23, No. 7-8. pp. 499-521.

\section{Introduction}

[p. 1] Emerging industries are not rare elements in the economy or society. Rather they constitute a permanent feature in a constantly developing and changing economic environment. Thus they should be considered a key component to economic change in generating new products, services, businesses and employments. However, the emergence of new industries is rarely painless or particularly straightforward and there is no simple recipe to guide an emerging industry. Actors involved in these processes are confronted with difficulties of which some are exclusive to emerging industries and some are not. Firms, entrepreneurs and labour are exposed to uncertainty since emerging industries lack established structures and institutional frameworks and standardized or settled procedures and processes (Clegg et al. 2007). Also, an interesting and challenging dimension of emerging industries is that they are often confronted with an unsympathetic, or at best curious, environment. Lack of industrial legitimacy is often a source of uncertainty in emerging industries and "new organizations are always vulnerable to the liabilities of [p. 2] newness, but such pressures are especially severe when an industry is in its formative years" (Aldrich and Fiol 1994:645).

A distinctive example of the processes of newness and emerging industries is the internet industry in Stockholm, Sweden, which emerged during the latter part of the 1990s and the early 2000s. This development was driven by and dependent on entrepreneurs and the internet firms was embedded in uncertainty in such way that they needed to be innovative, flexible, creative, ideas driven, and continuously changing in order to deal with for example new technology, emerging markets and new ways of organizing labour. In studying the life cycle of an internet firm Drori et al (2009:716) states that, "changes in the institutional environment during the early days of the internet involved a period of uncertainty and vulnerability". Furthermore, the level of uncertainty was amplified in that no industry have had the same pace in the circulation of ideas or the same momentum in the product life cycle as the internet industry (Neff 2005).

Another distinctive and important characteristic of the internet industry is the high concentration of firms in agglomerations, mainly larger cities (Jansson 2005; Moriset 2003; Neff 2005; Zook 2002). In its formative years the internet industry in Sweden was densely located in the agglomeration of internet firms in central Stockholm. In 2002, more than half of the population of internet firms in Sweden were located in the Stockholm region and 
employing more than $60 \%$ of the people working in the internet industry in Sweden (Jansson 2005).

Theoretically, this article draws upon economic geography literature on agglomerations and concentrations of economic activity where the topic of uncertainty is rather neglected. Thus, this article argues that the local milieu plays a crucial role to actors coping with uncertainty. Agglomerations, i.e. spatially concentrations of firms (and labour) in similar or related activities, and the urban space with its diversified supply and demand, form a rich network of contacts and possibilities that may help in reducing uncertainty. Also, and more specifically, the article examines the ways that internet entrepreneurs cope with uncertainty through the study of three separate (but related) and industry specific types of uncertainty. The study of the emerging internet industry in Stockholm shows that internet entrepreneurs was exposed to uncertainty due to a) the newness of the technology introduced to the public and the emerging markets during its formative years in the late 1990s and the years following the turn of the millennium. The structure of the internet industry had not gone through processes of standardization and the surrounding society had not had the time to adjust to the radically new products and services springing from the internet technology; b) these non-standardized products and services made the creation and establishing of new markets and new customers problematic. Accessing customers was a matter of uncertainty since most customers were ignorant about the advantages of internet as a communication and distribution vehicle; c) the introduction of internet technology and the development of the internet industry stood for an ambitious criticism of pre-existing structures such as traditional ways of organizing business, work and labour.

The article starts with a literature review over research dealing with emerging industries and uncertainty, especially within the field of economic geography. This section is followed by an attempt to create a theoretical framework by using various levels of internet industry specific uncertainties. The methodological section discusses both the quantitative and qualitative research used in the study of the internet industry in Stockholm. The empirical sections are introduced by a description on the size, localization and development of the internet [p. 3] industry in Stockholm. This is followed by analyze of the internet entrepreneurs coping with the uncertainties of new technologies, market relations and labour market in the emerging internet industry. Finally, concluding remarks are drawn on the relation between agglomeration and uncertainty.

\section{Emerging industries, uncertainty and economic geography}

It is rather impossible to make any clear cut definitions of emerging industries. First, this is due to the sheer fact that emerging industries could be made up of any new type of products or services. Second, there is the question of how you define the start of an industry and what is actually new in an emerging industry? Related to this question is also the hard to define distinction between an emerging and a mature industry. Third, how are industries defined; are we talking about a certain set of firms and actors, or a certain way of doing things, or even a certain set of skills and knowledge?

Nevertheless, the majority of the studies made on emerging industries deals with uncertainty (or risk) in one way or another. However, there is a distinct difference between 
uncertainty and risk. Where risk is knowable, calculable and probabilistic and uncertainty is non-knowable and refers to situations where risks cannot be expressed in terms of mathematical probabilities such as the outcomes of sport events, elections or investments.

From the literature on emerging industries four main topics may be identified. First, research on emerging industries has brought up the question of identity formation (Clegg et al. 2007) i.e. strategies used by actors and institutions to achieve legitimacy for new activities (Dejean et al. 2004).

A second strand of literature raises the question of knowledge flows, distribution, management and dynamics in emerging industries. Izushi and Aoyama (2006) examine the interrelationship between technological progress and the formation of industry-specific skills in their study of the video-game industry in three countries. The authors state that national contexts, such as the social legitimacy and strength of pre-existing industries and the socioeconomic status of entrepreneurs or pioneer firms in an emerging industry, has an effect on cross-sectoral transfer of skills. Other research put emphasis on how uncertain environments of emerging industries require both organizational capacity for learning and innovation, and flexible adaptation to constantly changing requirements (Girard and Stark 2003). Further research within this field have studied topics of knowledge diffusion in open source software development projects (Sawabe and Egashira 2007), and the role of inter-firm relational skills (Patchell 1999).

The third category focuses on exogenous factors such as financing and customer related variables (Lasch et al. 2007) or institutions (Murtha et al. 1996). For example, Schill and Zhou (2001) study the financial side of emerging industries in discussing the difficulties in estimating economic values of new types of activities and Maksimovic and Pichler (2001) research different types of funding and financing of emerging industries depending on the risk involved in the investment. In general, it can be stated that discontinuous growth is common and that the volatile environment of an emerging industry presents particular problems to [p. 4] young firms which have not yet built up the strength to sustain them through short-term crises (Garnsey and Heffernan 2005).

Finally, different performance-measures between emerging industries and 'traditional' or pre-existing industries are analyzed. For example, McGahan and Silverman (2001) compare patent activity between mature and emerging industries.

Thus it seems that studies on emerging industries tend to focus on the insecure and fast changeable contexts that seemingly characterize emerging industries. Also, this short and by no means all-embracing literature review reveals that only a few studies within economic geography is focusing on emerging industries.

\subsection{Uncertainty and Economic Geography}

Although relatively neglected within economic geography, uncertainty may arguably be used as a variable explaining the structure and development of emerging industries. In the following I will show how the concept of uncertainty (or risk) has been problematized and used within this field.

Many aspects of uncertainty are founded in the everyday transactions and socioeconomic networks that characterise a creative and dynamic local industrial milieu (Crewe 
and Beaverstock 1998; Scott and Walsham 2005). Early attempts made by economic geographers, to make reason of the concept of uncertainty, have examined this in the context of labour markets. For example, Allen and Henry (1997) studied changing contractual forms in the UK labour market and state that contract labour flexibility should be understood as insecure.

Also, there are a limited number of studies of uncertainty and cultural industries. An interesting attempt to analyse spatial aspects of uncertainty is made by Banks et al. (2000) who states that cultural industry firms are characterised by taking risks and chances in their continuously need to be innovative, flexible, creative, idea driven and constantly be prepared for change and adjusting to new circumstances. A similar line of argument is used by Ekinsmyth (2002) who find linkages between uncertainty and project organization in the magazine publishing industry. The exposed position of many newly established firms and industries has to do with their activities being judged by subjective and unpredictable markets where the value of a product is estimated by, for example, esthetical appraisals. This argument is supported by Scott who states that uncertainty constitutes an essential component in aesthetic activities and that this is much to do with "the fickleness of consumer tastes" (Scott 2006: 12) in that the cultural industries often are object to swift changes in preferences, fashion, taste and attitudes. At the same time, the main achievement of many cultural industry firms is rather to set and keep a position as creatively leading and relevant, than maximizing revenue (Crewe and Beaverstock 1998). Uncertainty is also linked to the idea of reputation which is an important factor in the local and increasingly also the global milieu (Scott and Walsham 2005). Penfold (2002) argues that risk management and structures of control in the production chain will explain the spatial distribution of firms and economic activity in a more sufficient way than traditional variables like transaction costs or agglomeration economies.

An attempt to link uncertainty with economic activities and agglomeration has been made by Strange et al (2006) in studying how agglomeration economies may arise from uncertainty. They construct a model out of three variables - competitive instability, need for skilled workers and technological [p. 5] innovativeness - that captures uncertainty-driven agglomerations. In the findings they show how firms facing more uncertainty will agglomerate within large cities or industry clusters while firms facing less uncertainty will be located in smaller cities or outside dense industrial clusters.

As shown, there are only a few studies focusing on the relation between uncertainty and agglomeration in economic geography. However, as I will try to explain below there are reasons to believe that uncertainty constitute an important variable in explaining agglomerations of emerging industries. By developing a theoretical framework, using three internet industry specific aspects of uncertainties, this article aims at discussing the agglomeration of internet firms in central Stockholm and the way internet entrepreneurs use their local milieu in order to cope with uncertainty.

\section{Agglomeration and uncertainty}

The internet industry has a strong tendency to agglomerate in big cities and national centres. This location pattern is also evident at national level which is empirically shown in numerous studies on the internet industry and related industries such as the new media, multimedia, and 
graphic design industries (Jansson 2005; Leamer and Storper 2001; Malecki 2002; WolfPowers 2001). Additionally, the internet industry show a specific localization within the cities where they are located. Within these cities internet firms tend to concentrate to certain districts or quarters (Jansson 2005; Moriset 2003; Naylor 1999; Neff 2005; Zook 2002). This localization is not only typically to the internet industry, but have similarities to a number of industries such as the music industry (Power and Hallencreutz 2002), the fashion industry (Rantisi 2002) and other creative industries (see Gibson et al., 2002).

The advantages of being located in agglomerations have been discussed through specialization (Marshall 1890/1916) or diversity (Jacobs 1969). Within the specialization literature three variables have traditionally been acknowledged; (lowering) production costs and costs for transport and transactions as well as the emergence of qualified and specialized in local labour markets (Marshall 1890/1916; Scott 2001; Storper 1995). More recently, agglomerations has been explained through firms' innovativeness and ability to continuous learning in interaction with other local actors in various system approaches (Lundvall 1992, Maskell et al. 1998; Porter 1990). The literature on diversity (or urbanization economies) has stressed the advantages of being located near a range of different industries in the process of innovation (Cooke 2008), but also the advantages of being located in proximity of the multiple variations offered by urbanization economies (Jacobs 1969). Much research has, in line with Granovetter (1985), emphasised the importance of the social embeddedness of local processes.

A number of different studies, both empirical and theoretical, have tried to unfold the mysteries of agglomeration and most studies are involved with the question of what is gained through being located near (both physically and culturally) customers, suppliers, competitors, institutions etc (Corolleur and Courlet 2003). Recent studies focuses on how face-to-face contacts are facilitating access to knowledge and knowledge exchange in the local milieu, but also access to local 'buzz' (Storper and Venables 2004). In many studies the question on knowledge flows has been discussed through the concepts of codified and tacit [p. 6] knowledge (Gertler, 2003). Also, agglomerations are understood not only as gaining access to local networks and knowledge, but also in facilitating crucial external (global) linkages (Bathelt et al. 2004).

More specifically, variables explaining agglomerations of internet firms include access to financing and venture capital (Zook 2002), tacit knowledge and customers (Jansson 2008). For example Moriset (2003 p. 2172) states that "providing corporate services in electronic business intelligence or communication is the very raison d'être of internet companies". The importance of informal local labour market matching processes is viewed as important variables in explaining internet industry agglomeration (Jansson 2005, Neff 2005).

In the following I will argue for uncertainty (Knightian uncertainty) as an explanatory concept analyzing the importance of agglomerations (spatial proximity) in coping with uncertainties and formative processes of emerging industries.

\subsection{Negotiating industrial structure and legitimacy}

Lack of legitimacy is a crucial uncertainty to emerging industries (Dejean et al. 2004). Drori and Honig (2007) make a distinction between external legitimacy, which may be obtained 
through cognitive processes and cultural accounts, and internal legitimacy, which relates to external forces, but ultimately established within organizational boundaries. Thus, legitimacy relates to the social or societal perception of or assumptions about the activities or outcome of (industrial) organizations within socially constructed systems of norms, values, beliefs and definitions. "Legitimacy is a relationship between the practices and utterances of the organization and those that are contained within, approved of, and enforced by the social system in which the organization exists...Legitimacy ultimately exists in the eye of the beholder". 'Social systems' could be broadly defined as political and regulatory, product, labor, financial, technological, social tastes and preferences, and the like, but also on different spatial scales such as international, national, regional, or local (Zimmerman and Zeitz 2002:416). Aldrich and Fiol defines two types of legitimacy; cognitive - knowledge about a new set of ventures and products/services, and sociopolitical - how the new ventures are accepted by society and formal authority (Aldrich and Fiol 1994:648).

Emerging industries may not only lack legitimacy, also there are no structures and procedures of how things should be done. Such structures, procedures and legitimacy have to be negotiated both within the industry and in relation to the surrounding society. Arguably, the negotiation of new structures and routines is facilitated by being located in information intensive urban milieus and agglomerations. In order to sort information and interpret knowledge flows, actors involved in emerging industries are facilitated by dense concentrations of internet firms, entrepreneurs and labour which constitutes a supportive environment where entrepreneurs and labour could get support for their ideas and behaviour. Thus, entrepreneurs and other people working in emerging industries are supported by being among others doing similar things. Pratt (2006: 1892) states that 'peer regard' (in the advertising industry) is a "process of checking, scanning, and evaluating others against a perceived ideal or aspiration", and compared to many other industries this ideal might change frequently, even from week to week. Peer regard [p. 7] works as an indicator of what is considered to be a qualitatively successful product or practice and thus necessary ingredient in the negotiation process of an emerging industry. Peer regard is dependent on information such as gossip and informal discussions between peers and colleagues in their working and private life. These processes are facilitated by proximity and face-to-face interaction which is particularly important in environments where information is imperfect, rapidly changing, and not easily codified; key features of many creative activities (Biggiero 2004; Gertler 2003; Storper and Venables 2004). For example, creative or cultural production is inherently dependent on the 'hypersocialized' social milieus for more than informal knowledge exchange, but also as platforms for production, innovation and valorization (Currid and Connolly 2008). Nevertheless, one should not neglect the fact that many firms, entrepreneurs and creative people are open to influences and knowledge flows from distant locations in 'communities of practices' (Brown and Duguid 1998) or 'pipelines' (Bathelt et al 2004).

\subsection{Discovering opportunities and markets}

Discovering opportunities is fundamental to entrepreneurship and Eckhardt and Shane (2003:336) defines 'entrepreneurship' as “the discovery, evaluation and exploitation of future goods and services" and consequently they define 'entrepreneurial opportunities' as 
"situations in which new goods, services, raw materials, markets and organizing methods can be introduced through the formation of new means, ends, or means-ends relationships". As such, these processes are uncertain in that entrepreneurial opportunities "cannot be exploited by optimizing because the set of alternatives in introducing new things is unknown, precluding mechanical calculations between all possible alternatives" (Eckhardt and Shane 2003:336).

In a relational constructionist perspective, entrepreneurs create opportunity in interaction with their surrounding environment. Opportunity discovering is defined as a social/relational process in which the entrepreneurs are constantly relating to things around them (Bouwen 2001; Fletcher 2006) and also embedded or situated (localized) in regional/spatial contexts or settings (Jack et al. 2008; Zafirovski 1999). In the same line of arguments new ideas and innovations are rarely a result of a sole genius. On the contrary they are more likely to occur in interaction with the surrounding society or more specific; systems of embedded firms, entrepreneurs and other relevant actors, at various (local) spatial scales; nations, regions, urban areas or districts (Maskell and Malmberg 1999).

A specific and crucial part of discovering opportunities is the creation (or discovering) of new markets. To an emerging industry, making markets and persuading potential customers is a matter of legitimacy and trust "as both entrepreneurs and crucial stakeholders may not fully understand the nature of the new ventures" (Aldrich and Fiol 1994:645). Drori et al. (2009:715) continues this idea and states that "acceptability by various social actors helps provide capital, access to markets, and legitimacy". Getting in contact with and finding ways through the market is much about getting access to the 'buzz' (Storper and Venables 2004) or 'noise' (Grabher 2002) circulating within a local milieu. To small enterprises with limited resources locally embedded networks constitute a crucial source of information in keeping them up-to-date with the latest developments and changes (Julien et al. 2004). It is thus important to become an 'insider' [p. 8] in order to get access to the right type of information and knowledge. However, becoming an insider requires an understanding of the larger collective (network), its norms, language and culture of a certain industry. A process highly facilitated by both physical and cultural proximity between actors (Jansson 2008).

As already mentioned, emerging industries involves non-standardized products and services, and to be able to communicate these products and services to potential customers there is often a need for trust between sender and receiver. This type of informal relations is often easier to establish in local milieus which promote understanding and trustworthiness between different actors (Watson 2008; Wolfe and Gertler 2004).

\subsection{Uncertain labour market relations}

Uncertainty also concerns the volatile labour markets that may arise in relation to emerging industries. To cope with uncertainties related to the labour market of emerging industries entrepreneurs to a large extent depends on temporary structures such as short term projectbased organisation of labour and 'ad hoc' solutions (Girard and Stark 2003). Temporary systems (Goodman 1981) or temporary organisations (Ekstedt et al 1999) involves several people, and maybe even more important, several types of skills and competences. A project is 
also limited in time when the team of different people and skills (usually hand-picked) is disbanded when the job is done. Project teams are often a result of well established and embedded, long-term relation between the individuals engaged in a project (Sydow and Staber 2002). Assembling project teams is a matter of activating existing informal networks and relations; relations that is more easily established between proximate individuals. Grabher (2002:253) argues that "the more relations are driven by availability and speed of delivery, the more project networks gravitate towards local concentrations of specialists, professionals and service firms". Hence, co-location or project partner become important in coping with short term project cycles and unforeseeable processes.

In fluctuating and unpredictable industries where creativity is a crucial input and no formal requirements on the competence and skills of the labour force are settled or standardized it is important to have access to a broad roster of different labour or what Caves (2000), in his analysis of the cultural industries, refers to as a 'motley crew'; the vast range of competences and resources required for production.

The temporary characteristic of project based work challenges some common assumptions about work organization, especially learning in economic geography research (see Maskell and Malmberg 1999; Morgan 1997), but also in literature concerning locally embedded industrial districts (Boschma and Lambooy 2002). This literature tends to emphasize long-lasting relations which generate trust and sequentially learning and innovations, especially in complex processes. Although projects are limited in time and participants are separated after the project is finished there is a process of knowledge creation and learning that might be accumulated within labour networks (Grabher 2004).

\section{Methodology and empirical reflections}

Emerging industries should be viewed as complex environments in which many influences interact (Zimmerman and Zeitz 2002) and arguable, such complex [p. 9] contexts are well suited for qualitative and narrative approaches (Tsoukas and Hatch 2001). Also, case study methodology is well suited to an exploratory approach which is useful in the study of new and emerging economic activities. This study, however, employs both qualitative and quantitative methods in order to illuminate both the structure and processes involved in the emerging internet industry. The empirical material presented in the following sections is based on a study of the internet industry in Stockholm completed between 2000 and 2005.

\subsection{Data collection and definitions}

In the initial and quantitative phase of the study, statistical sources were employed in order to a) define the emerging internet industry as such, b) basic description of the industry e.g. size and localization (see section 5.1).

The definition was operationalized by using the database Affärsdata; a public registers including data from Swedish patent and registration office with information on all Swedish firms. Through this database a search was made of the firms' articles of association. By using a number of concepts, like 'internet', 'web', 'interactive' and similar concepts the internet companies was singled out from the rest of the companies. Three main categories of 
internet firms were identified; web design, on-line business solution consultancy, and content providers. Using this definition, information on firms' size, age, and number of employees was gathered from Affärsdata.

The newness of these activities in combination with the lack of relevant nationally or internationally recognised definitions or industrial classifications made it problematic to achieve an adequate conceptual and operational definition of the internet industry (Jansson 2005). However, the research presented in this article defines the internet industry as: firms whose activity/existence is dependent on the internet and whose production and distribution of goods and services are dependent on the internet i.e. firms that produce goods and service for and through the internet. This definition was used to get hold of firms which are truly dependent on, and arising from the internet, but also to distinguish the internet industry from a) the wider ICT-sector (OECD 2002; Winther 2001) and from b) research using for example company web pages as a measurement of the size of the internet economy (Zook 2000) or adjacent, but not identical, definitions like for example the multimedia industry (Sandberg, 1999).

The qualitative part of the study is based on an interview study conducted in 20002002. Initially, a pre-study was made based on ten interviews with industry organizations and other industry related spokespersons in order to gain insights in the overall development of the internet industry. This part of the interview study also informed the definition of the internet industry. Sequentially, 30 entrepreneurs involved in internet firms were selected and interviewed. The firms in the study were selected to cover the categories that made up the definition of the internet industry i.e. ten interviews per category. Since a goal of the study was to examine the existing agglomeration of internet firms located in the central districts of Stockholm all respondents were involved in firms located in this area.

With a few exceptions, the interviews were made with the founder or CEO of the firm, henceforth referred to as (internet) entrepreneurs. All respondents had experience from running internet related businesses (ranging from one to six years at the [p. 10] time of the interview) as CEO or founders of an internet company. Most respondents also had experience from being employed by other internet businesses. Thus, the internet entrepreneurs that were interviewed had personal knowledge and insight in the development of the internet industry in Stockholm. All but two of the respondents in the interview study were men, age 25 to 50 . This may represent the share of CEOs or founders of internet firms, but do not represent the proportion of men $(71 \%)$ and women $(29 \%)$ working in the internet industry.

The interview study was informed by participant observation methodology (Frankfort-Nachmias and Nachmias 1996) and thus face-to-face meetings with the respondents were important. All interviews were carried out in the office space of respective internet firm which gave insights in how firms choose to express themselves through office space organisation and interior design, but also to get insight in hierarchical structures of the company and appearance of their colleagues. In a 'dialogical method' (Mugerauer 2000) the intention is to create a situation where the interviewer and the respondent feel at ease and are able to have a relaxed conversation where the interviewer can get access to and understand business milieus and their cultures. 
A major aim with the interview study was to capture the development of the emerging internet industry and understand it from its relation to the local environment, and thus to understand the internet entrepreneurs' ideas about the development of the internet industry and their view of how their firms development in relation to the surrounding society, the internet industry and the labour force. The interview study employed a semi-structured interview technique (Bryman 2004) which is based on an 'interview guide' including the topics of interest regarding specific research questions. The interview guide used was structured around insights made from the pre-study in combination with an extensive literature review. Key themes in this interview guide were aspects such as formal and informal contacts with suppliers, customers and labour, knowledge flows, labour market and localization/agglomeration issues. The advantage with semi-structured questions is the flexibility and that it gives the interviewer the opportunity to let the respondent lead the conversation as long as all topics in the interview guide are checked. This flexibility gives the respondent a chance to explain what he or she thinks is relevant and important (Alvesson 2003).

In addition to the statistical data used and the interview study, literature and media such as industry magazines, journals and television were examined to get input to the general understanding of the internet industry and its development.

\subsection{Data analysis and generalization}

The process of analyzing the interview material has, of course, been affected by the categories used in the interview guide and the ideas behind the study. However, the interviewees and their responses, the themes they brought up, and the way they expressed themselves have also influenced the analysis. A main aim with the analysis has been to look for and interpret the material for patterns where the respondents seem to have an approximate same idea of how things are working within the industry (Alvesson 2003).

However, interviews (as any other research method) should be considered with caution; they are hardly are straightforward techniques for draining respondents [p. 11] of information. "Social and linguistic complexities should not be seen as just sources of bias. The interview as a complex social event calls for a theoretical understanding or, rather, a reflexive approach in which a set of various theoretical viewpoints can be considered and, when there are reasons for doing so, applied" (Alvesson 2003, p. 14). Thus, a more reflexive conclusion is that the material used in the article should be viewed as the interpreted and restructured version of already subjective opinions about the internet industry during its initial, formative years. The analysis and conclusions drawn from the interview study are thus embedded in the researchers own knowledge frame.

Considering the size of the internet industry in Stockholm and the size of the interview sample, the results from this study are hard to generalize to other industries and to other spatial concentrations of internet firms. However, the results may say something about the processes of internet entrepreneurs coping with uncertainties in emerging industries.

\section{Coping with uncertainties}


In the following empirical sections the analysis is mainly based on the interview study described in the methodological section. In addition, it is informed by observations made during the meetings with respondents and insights made through scanning industry journals and media. Using theoretical/analytical concepts such as negotiating legitimacy, peer regard, insider and trust, the aim of the empirical section is to give a picture of how internet entrepreneurs use the local milieu and spatially proximate relations to cope with uncertainty related to new technology, new customer/market relations and the development of a complex and informal labour market.

However, by way of introduction, the analysis will be contextualized by a general descriptive section of the emerging internet industry in Stockholm. This section is informed both by quantitative and qualitative data described in methodological section.

\subsection{The internet industry in Stockholm}

In the initial years of the 2000's Stockholm became known as one of the most innovative cities within ICT and the internet. The magazine Newsweek declared Stockholm as "Europe's Internet Capital" and promoted the city as a dynamic and world leading internet cluster with internationally leading cutting-edge firms (Newsweek, 2000). In addition to the internet cluster, Sweden and especially the Stockholm region were also known for having a strong and dynamic milieu within mobile communication (e.g. Ericsson) and other ICT related activities. Furthermore, during this period internet penetration in the Swedish society was, in comparison with other OECD countries, very high (National Post and Telecom Agency 2002; OECD 2002). These circumstances paved the way for many Swedish internet firms by allowing firms to use the relatively sophisticated customer level as a test-bed for new products and services.

A number of new forms of economic activities developed, both directly related to the development of the actual technology, but also related to the possibilities of using the internet in various ways (such as web design bureaus, content provider and e-business firms). Due to the newness of the technology and the speed of technological change, [p. 12] no formal or informal structures were established around the new industry. In addition, the industry was exposed to uncertainty in that the technology was new and constantly changing at a pace that was not recognisable from most other industries. Also, technological development and its impact on society were under constant scrutiny and thus further boosted the internet industry as a chaotic and highly unpredictable environment.

In this study the internet industry is defined as economic activities/firms whose existence (production and distribution) is dependent on the internet; economic activities that are independent from physical space and thus able to locate anywhere. As such, these activities are involved in the production and distribution of goods and services for and through the internet. In the internet industry in Stockholm three main types of firms have been identified. The web design category is represented by design and idea intensive firms working with design of web sites and pages, graphic design and on-line advertising. Firms in the online business solution consultancy category can be divided into firms working with business solutions, software systems, and internet security. Compared with the former category these firms are more technology driven, although still dependent on design and aesthetics. The 
category of content providers includes a wide range of activities; news and entertainment, portals, search engines, on-line games etc.

\section{Insert Table 1 about here}

In same fashion as existing research, this study shows that the internet industry in Sweden is concentrated to certain locations. In 2002 as much as 55\% of the internet firms were located in the Stockholm region employing more than $62 \%$ of the people working in the industry in Sweden. On a more narrow geographical scale, approximately 30\% of all Swedish internet firms are concentrated to the central districts of Stockholm, in particular near certain streets in the districts of Södermalm, Östermalm and Norrmalm. Furthermore, 80\% of all internet firms' employees are concentrated to the three largest city regions in Sweden (Stockholm, Göteborg and Malmö) (Jansson 2005). All in all 474 internet firms were located in central Stockholm in 2002 and the amount of employees in these firms was 6195 (table 1).

The statistical analysis also show that the average size of internet firms in Stockholm (in 2002) is relatively small with approximately $50 \%$ of the firms employing five people or less and only about $4 \%$ employing more than 50 people. Naturally, the majority of the firms in the sample were established after 1994 with a peak around 1998-99 and some firms established even after the millennium. Only a few of the firms were established before 1996 and some even before 1994, although these firms have changed their direction according to the new technology. As a consequence of internet firms being micro or small sized, entrepreneurs often shoulder the role of not only the business' manager, but also its administrator, customer contact person and innovator or developer of new products and services.

[p. 13] The industry's focus on content and design provision makes it more similar to the cultural or creative industries than the more technology and research driven ICT-sector. For example, interviews with the internet entrepreneurs show that the activity of the internet firms discussed in this paper is characterized by a production system which is almost always organized in dense networks of small and medium sized firms which are strongly dependent on each other for specialized inputs and services. These networks tend to put forth vast demand on the local labour market and to require a range of skills and qualities. Employment relations are irregular, often organized in temporary organisations or project work. This leads to frequent job search for internet labour and recruitment activities for entrepreneurs and employers. Another characteristic worth mentioning is the low barriers of entry. Since the costs of setting up a new internet firm is marginal, except from salaries, perhaps the most basic need for an internet start up is technology skills, competent labour and access to customers.

\subsection{Coping with new technology and techniques}

The actual introduction of the internet technology constituted a source of uncertainty in the emerging internet industry. New types of activities and companies developed which created a need for the industry to negotiate external legitimacy towards the society and new markets. 
Also, the development of new types of activities created a need for internal legitimacy within the industry.

In the case of the internet industry in Stockholm external legitimacy was about creating trust in an unknown technology - the internet. This new technology was often seen by outsiders with suspicion and a fundamental mission for internet entrepreneurs implied explanation and clarification of the possibilities and advantages with the internet, both in itself, but also in comparison to traditional media and technology. An important part of this process was a number of spokespersons (both self appointed and/or associated by accident) who communicated the message of the internet as the technology of the future. This communication was only possible being in the vicinity of media (Swedish media is highly concentrated to Stockholm), getting access to journalists, television, newspapers etc. channeling the message to the public, markets and other that needed to be convinced. In general this process was equally about marketing the internet; as it was about marketing the firms involved in making use of its potential. However, both the new technology as well as the emerging internet industry was exposed to harsh criticism, not the least directed towards their presence or non-presence at national stock-markets.

On the other hand, internal legitimacy was about setting up routines and standards of how to do things. This process was driven by the need for negotiating both functional and aesthetic values. The internet firms was involved in subjective and unpredictable markets in which the value of the product or service was hard to measure, benchmark and assess objectively or communicate in codified form. The formative development and internal legitimacy process of the internet industry was facilitated by the local milieu in that it functions as an important platform for the negotiation of how to structure the new industry, but also (and mainly) as a point of negotiation of which aesthetic and functional solutions that is or is not applicable [p. 14] to the new technology. This negotiation of information was facilitated by the urban milieu in Stockholm in that it offers meeting points such as a variety of entertainment, restaurants, seminars, conferences, as well as presence of media and other channels for transmitting information and knowledge.

There is always some kind of advantage with [internet] firms being concentrated in central Stockholm...it is enough to hang out, have a beer at the 'right' places and you will get informed with gossips and names.... and you will find your way into important networks (Interview with CEO of an on-line business solution consultant firm) ${ }^{1}$

Thus, informal infrastructures, such as the night life in Stockholm, works as a platform for information exchange and facilitating for 'buzz'. This local supply of information is crucial to small enterprises or self-employed entrepreneurs with limited resources as it gives opportunities to keep up to date with the latest development and changes.

Another important platform for negotiation is contests and awards which made up a crucial element from an early stage in the development of the internet industry in Stockholm. Contests and awards serve as filters and catalysts to sift out and highlight the ideas of

\footnotetext{
${ }^{1}$ All interview quotes used in this article are translations from Swedish to English.
} 
innovative firms (see Pratt 2006 for a more in depth analysis of the importance of awards). Internet industry contests and awards are important both to other internet firms in that they see what is going on in the industry, but it may also function as a marker to customers who buys products and services from the internet firms.

Of course it is easier if you win a prize. It is easier to motivate a customer to choose our company. The customer thinks: 'If they did a good job for another customer they may as well do it for us' (Interview with CEO of a web design firm).

As such, the process of negotiating functional and aesthetic solutions of products and services is a social process where competitions, awards and other arrangements such as network meetings and other meeting point represent crucial platforms for negotiating standards for evaluation of standards for functionality and aesthetic appreciation.

However, in the case of the internet industry one should not neglect the fact that the process of negotiating functional and aesthetic values is not entirely dependent on local actors. The study also show that negotiating industrial legitimacy was dependent on widespread relations or 'communities of practice' through the internet at web-based sites, communities, and portals.

\subsection{Coping with emerging customer relations}

Another source of uncertainty in the internet industry is external legitimacy which involves the process of accessing new markets and clients. Since the internet technology was new, reaching customers was about getting the customer understand the advantages of internet as a valid communication and distribution vehicle. In many ways this was a process of persuasion which involved the power of creating trust between the actors involved.

Internet entrepreneurs working in Stockholm often faced a situation where demand from (potential) customers was far from sophisticated. Put simply; 'customers did not know what they wanted'. However, in the case of the emerging internet industry and the proclaimed 'digital revolution', there was one thing they [p. 15] knew: 'they had to do something'. The internet was emphasized as the most important new technology in decades and internet presence' was repeated as a key to future business fortune. Hence, the internet quickly became a bandwagon you just could not ignore in order to meet the demands of the "new economy'.

I started my firm in 1996, so I have been in the business from the start so to speak, and initially the customers did not know anything about what they needed, why and how much an internet investment may cost (Interview with CEO of an on-line business solution consultant firm).

However, even if the customers knew they had to do something, the internet firms still had to persuade potential new customers to use the internet for their business and communication. The relation between internet firms and potentially new customers was difficult not only because the technology was new, but also because many of their products and services were complex. To be able to convince customers about their products and services the internet 
firms had to initiate close and informal relations necessary in creating trust which is crucial in the sales of more complex products and services.

\footnotetext{
To me, personal relations are utterly crucial...if you become friends, you will probably end up doing business as well. But if I just send a proposal to anyone I could just as well throw it away. You cannot make a deal without actually meeting each other (Interview with CEO of an on-line business solution consultant firm).
}

Trust and informal relations was crucial not only in approaching a new customer clientele, but also later on in the process e.g. contracting. Whereas firms in mature and formally well structured industries often response to uncertainty by enlarging or joining legal and administrative units, firms in creative or cultural industries often lack resources to change the bureaucracy of their working procedures. Instead, they develop qualitatively strong and personal relations with their clients and individuals that they are comfortable with and are easy to cooperate with. In the internet industry in Stockholm, the trust between parties may be illustrated by the fact that formal contracts were rarely established in agreements with customers or co-operations with for example suppliers. The abrupt changes that characterised the industry were so frequent that there was almost no time to negotiate formal contracts. Lack of formal contracts was also rooted in the limited economic space of a firm or a project. One of the interview firms answered the question what type of contracts they signed with their suppliers:

\footnotetext{
We never sign formal contracts. But you agree upon something and it is very much about if there is someone that you have confidence in. You have a relation. If you ask a supplier how long a job will take and he replies that it will take $\mathrm{X}$ hours and cost $\mathrm{X}$, you have to trust that he will not spend more hours so that you have to spend more money than agreed upon (Interview with managing director and founder of a web design firm).
}

Keeping informal agreements strict and thus making the parties trust each other was crucial, but it was also important to make the agreements flexible so that the agreements may be changed if and when new instructions were commanded. Agreements made with suppliers and freelancers were rarely exclusive. Hence, informal and loose agreements, short-term contracts and the unwillingness to establish formal relations and long-term contracts with customers, suppliers and partners was one way firms try to minimize uncertainty in an unpredictable economic context. This solution made it possible for all parties to quickly get out of [p. 16] an agreement if the project is not profitable or interesting to the firm, or just have the option to 'leave a sinking ship'. However, it should not be neglected that many internet firms suffered from reputation of not be able no deliver in time and at the time media frequently reported on internet firms' inability to supply its clients with functional solutions in time and within agreed cost limits.

In general, and perhaps most important, the relations between the internet firms and the entrepreneurs running these ventures were about negotiating the value of internet products or services offered by internet firms i.e. how much are you supposed to pay for a functional 
and aesthetical appealing product or service? In an emerging industry such complex processes is dependent on proximate relations and this is especially so in the case of the internet industry in Stockholm where the majority of customers were located in the same region as the internet firms themselves.

However, although the local milieu certainly composed an effective platform for the negotiation of the value of products and services supplied by internet firms, it is also obvious that these processes did not always work properly. An illustrative example of such a relatively inefficient negotiation process was that many of the internet companies in Stockholm that received venture capital in the emerging stage of the internet industry did not manage to survive the burst of the bubble in the beginning of the 2000's. The main reason behind this development was the expectations and demands that were put on the internet companies regarding their growth and profits. As these demands were too high venture capitalists pulled their investment after the internet bubble burst. Apparently, also venture capitalists had difficulties understanding and estimating the potentials and value of the internet technology and the firms' activities related to the new technology.

\subsection{Coping with labour and work organisation}

At the level of internet entrepreneurs, the interview study revealed that labour market uncertainty was due to a) the number of employees needed to meet customer demand, and b) labour force requirements and qualifications needed to meet demands from fluctuating and unpredictable markets, especially when the emerging industry is based on new and rapidly changing technology which, in turn, leads to continuously shifting demand for new products and services related to the new technology.

The internet industry, being at the epicentre of the 'new economy' during the latter half of the 1990's and the beginning of the 2000's, makes an interesting object of study because the industry represented, to a certain degree, an ambitious repudiation from preexisting structures. However, old structures are hard to change, both considering old technological systems and traditional ways of organizing work and labour. Internet entrepreneurs adopted project work organization and new perspectives of employment security which stood in stark contrast to common behaviour within the Swedish labour market and the 'Swedish model' (Anxo and Niklasson 2006). These developments led to a situation where almost every move made by the internet firms was 'ad hoc' and made into the 'unknown'.

The advantage with project organization is that firms are able to adjust the size and structure of the organization to meet the demand from an unpredictable client base. This organization structure has consequences for the conditions of the labour [p. 17] force in such a way that it becomes exposed to a riskier labour market with an increased proportion of insecure employment. In the internet industry in Stockholm contacts in the production and creative networks are, with few exceptions, established on informal basis. Generally no agreements are settled without having an already established contact between the firms (or more correctly; individually established contacts with each other). 
It is about personal networks all the time. Someone who works here has been working in another place and knows someone who knows a freelancer they hired before, or some other person who is available. Personal recommendations carry great weight if someone says; 'this guy is good' (Interview with founder of a web design firm).

Thus entrepreneurs tend to work with actors they know (preferably on a personal level) from previous contacts. This is especially important when a project team is composed by people outside the specific firm such as freelancers and other firms employed for a specific project. This is to do with the risk of getting ideas stolen or spread to 'wrong' people is increased when the actors involved are unfamiliar with each other. Thus project teams are made up of suppliers, freelancers and co-workers that are known from before and have been employed before, and within groups where 'everybody knows everyone'. Through these processes both reputation and competences are spread which leads to a situation where it can be extremely hard for an outsider to find their way into already established networks. Consequently, being located in dense social milieus are crucial in becoming an 'insider' which might get access to relevant information and knowledge.

In temporary organisations it is crucial to be able to rapidly put together new project teams in order to meet the demands from different customers. Therefore, internet entrepreneurs need to constantly keep their eyes open for potential customers and new labour contacts in order to widen their roster. Another strategy for internet entrepreneurs to lower their risk of having to employ too much staff it is common to use an already established set of people of whom they know who they are, how they work and what they know and are capable of. Some internet entrepreneurs for example use freelancers strategically on an almost permanent basis e.g. letting them using an 'own' desk at the firm. The implication of this is that they are available to the firm as if they were employed, although without the support of an employment such as administrative services and social security benefits.

Within the internet industry in central Stockholm work tends to be organized in both internal and external projects meaning that firms remain relatively small and lack people and competences to finish specific projects. This situation increases the demand for external projects where more actors than the individual firm are participating in the project.

\footnotetext{
We have a wide competence within the firm, and cutting edge knowledge in some areas, but we cannot afford to be best in all areas. This is why we work with partners such as other firms or freelancers. If we are doing a large project we bring in our network to cover the lack of competences and labour (Interview with managing director and founder of an on-line business solution consultant firm).
}

By using flexible labour internet entrepreneurs are able to meet different demands. Thus freelancers and other flexible actors are used to meet heights in the production. When a project is finished internet entrepreneurs are able to re-size their staff to meet the demand of the next project. The insecure market of the Stockholm [p. 18] internet industry, made it hard or impossible to predict the size and type of orders a firm would get. 
We [the firm] do not hesitate to take larger assignments. If times are changing and more assignments suddenly are coming in, we do have contacts to get the people we need....people we have worked with before, or even former employees (Interview with CEO of an on-line business solution consultant firm).

The up and down scaling of the number of employees as well as the often informal organisation of temporary project teams are facilitated and more effective, at least to the internet entrepreneurs, in local proximate milieus. However, seen from the perspective of the internet labour force these processes were not always positive. There was an increase of less secure and individualized employment contracts. Increased labour flexibility (e.g. working hours, working periods and skills) made it harder to plan and structure both work and everyday life. Also, to a certain extent the situation shifted the responsibility to search for and find new assignments and projects from the firm to the individual worker. Internet industry workers had to engage in the continuous process of finding new projects and work opportunities.

\section{Conclusion}

The aim of this study has been to show how entrepreneurs respond to and cope with uncertainties in the emerging internet industry in Stockholm. In particular an attempt is made to show in what way these processes have been facilitated by local milieus i.e. agglomerations. Three different, but related, aspects of uncertainty have been analyzed.

First, entrepreneurs in the emerging internet industry in Stockholm were exposed to uncertainty since the internet technology was new and thus related products and services. Continuous change and new technology in combination with an unaware customer base led to a state where each situation had to be negotiated and discussed in order to create norms and standards of how to do things. In this situation the local milieu in central Stockholm made up a fundamental infrastructure for creating spontaneous and formal meeting points where knowledge and information were effectively circulated, but also negotiated and discussed into strategies of how to do things in a new and emerging industry. This was a process of gaining industrial legitimacy; a process helped by peer-to-peer negotiation, arms length proximity and face-to-face contacts between the actors involved. Since most entrepreneurs and firms involved in the emerging industry were relatively small (number of employees, turnover) and resources scarce, the co-location of many actors involved in similar activities, using the same, new, technology, made the collective of internet entrepreneurs stronger and thus able to convince the market and surrounding society about the potential of the new technology.

Second, internet entrepreneurs were exposed to uncertainty in accessing markets and discovering opportunities related to the emergence of the internet industry. The development of the internet technology meant that entrepreneurs needed to convince their customer and environment about the advantages of the new medium. This process was further complicated for firms involved in the provision or development of complex products and services which require trust between the actors in order to be communicated. Trust is not easily established or communicated and is largely dependent on spatial and cultural proximity to become efficient. Getting access to the market is the same as getting access to relevant information which is 
most [p. 19] efficiently done by being an insider. Being an insider is crucial in getting the 'right' information and knowledge and becoming an insider demand close personal relations with other insiders of the industry. Thus, creating new markets and accessing new customers should be considered as a social and relational process and as such embedded or situated in spatial contexts.

Third, in order to adjust to fluctuating customer demand and to uncertain environments, internet entrepreneurs utilized project work and temporary organisations. Temporary organisations were necessary in order to both re-scaling the size of the firm, but also in being flexible in setting up new project teams with different skills and competence. In the emerging internet industry there were no formal procedures for finding relevant employees and thus informal contacts are efficient ways of getting relevant people into a project team. This situation put high requirements on the internet entrepreneurs in having a large network of people holding different types of competences. In particular, requirements of the width of the network is especially essential in market where no one knows what type of products and services that is demanded and thus what type of competences needed in putting together project teams for a specific assignment. Thus the urban local milieu offers an infrastructure for building informal networks in which internet entrepreneurs were able to find skills and competences necessary to meet volatile markets with rapidly shifting demands and possibilities. Vice versa one could argue that the local milieu also works in opposite direction; for internet labour to find project employment in an uncertain labour market.

To sum up, this article has tried to contribute to the understanding of how uncertainties of an emerging industry may explain, at least partly, why certain industries tend to agglomerate to specific cities or regions. The dense agglomeration of internet firms, entrepreneurs and labour in Stockholm constituted a supportive environment where entrepreneurs and labour could get support for their ideas and behaviour. Thus, entrepreneurs and other people working in the internet industry were supported by being among others doing similar things and maybe this was especially true with entrepreneurs in new and emerging industries which, as in the case of the internet industry, made themselves appear as revolutionary and distrusting old traditions and ways of doing things (advocates of the emerging internet industry claimed the 'new' economy at the expense of the 'old'). This process was assisted by being surrounded by peers where communication about gossip, information and knowledge about the industry was treated and interpreted. Also, being an insider is necessary in building trust between parties; crucial in approaching new markets and customers in rapidly changing environments.

Nevertheless, to better understand how different aspects of uncertainty may explain agglomeration more studies are needed. Especially, studies that take into account the three aspects of uncertainty discussed in this article; new technology, approaching new markets and labour market. These and other relevant aspects of uncertainty could be applied on other emerging industries than the internet industry to reach more in depth knowledge about emerging industries and agglomeration which are constant feature of the economy. 


\section{References}

Aldrich, H.E. and Fiol, C.M. 1994 Fools rush in - the institutional context of industry creation, Academy of Management Review, 19; 645-670.

Allen, J. and Henry, N. 1997 Ulrich Beck's Risk Society at work: labour and employment in the contract service industries, Transactions of the Institute of British Geographers, 22; 180-196.

Alvesson, M. 2003 Beyond neopositivists, romantics, and localists: a reflexive approach to interviews in organizational research, Academy of Management Review, 28; 13-33.

Anxo, D and Niklasson, H. 2006 The Swedish model in turbulent times: decline or renaissance? International Labour Review, 145; 339-371.

Banks, M., Lovatt, A., O'Connor, J. and Raffo, C. 2000 Risk and trust in the cultural industries, Geoforum, 31; 453-464.

Bathelt, H., Malmberg, A. and Maskell, P. 2004 Clusters and knowledge: local buzz, global pipelines and the process of knowledge creation, Progress in Human Geography, 28; 31-56.

Biggiero, L. 2004 Industrial and knowledge relocation strategies under the challenge of globalization and digitalization: the move of small and medium enterprises among territorial systems, Entrepreneurship and Regional Development, 18; 442-471.

Boschma, R. and Lambooy, J. 2002 Knowledge, market structure and economic coordination: dynamics of industrial districts, Growth and Change, 33; 291-311.

Bouwen, R. 2001 Developing relational practices for knowledge intensive organisational contexts, Career Development International, 6; 361-369.

Brown, J.S. and Duguid P. 1998 Organizing knowledge, California Management Review, 40; 90-111.

Bryman, A. 2004 Social Research Methods, Oxford. Oxford University Press.

Caves, R. 2000 Creative industries: contracts between art and commerce, Cambridge. Harvard University Press.

Clegg, S., Rhodes, C. and Kornberger, M. 2007 Desperately seeking legitimacy: organizational identity and emerging industries, Organization Studies, 28; 495-513.

Cook, P. 2008 Regional innovation systems, clean technology and Jacobian cluster-platform policies, Regional Science Policy and Practice, 1; 23-45.

Corolleur, F. and Courlet, C. 2003 the Marshallian industrial district, an organizational and institutional answer to uncertainty, Entrepreneurship and Regional Development, 15; 299-307.

Crewe, L. and Beaverstock, J. 1998 Fashioning the city: cultures of consumption in contemporary urban spaces, Geoforum, 29; 287-308.

Currid, E. and Connolly, J. 2008 Patterns of knowledge: the geography of advanced services and the case of art and culture, Annals of the Association of American Geographers, 98; 414-434.

Dejean, F. Gond, J.P. and Leca, B. 2004 Measuring the unmeasured: an institutional entrepreneur strategy in an emerging industry, Human Relation, 57; 741-764.

Drori, I. Honig, B. and Sheaffer 2009 The life cycle of an internet firm: scripts, legitimacy, and identity, Entrepreneurship: Theory and Practice, 33; 715-738.

Drori, I. Honig, B. 2007 The life cycle of internal and external legitimacy in a creative firm, Conference paper presented at the the Cornell-McGill Conference on Institutions and Entrepreneurship, July 2007.

Eckhardt, J and Shane S. 2003 Opportunities and Entrepreneurship, Journal of Management, 29: 333-349.

Ekinsmyth, C. 2002 Project organisation, embeddedness and risk in magazine publishing, Regional Studies, 36; 229-243.

Ekstedt, E., Lundin, R., Söderholm, A. and Wirdenius, H. 1999 Neo-Industrial Organising - Renewal by action and knowledge formation in a project-intensive economy, London, New York. Routledge.

Fletcher D. 2006 Entrepreneurial processes and the social constriction of opportunity, Entrepreneurship and Regional Development, 18; 421-440. 
Frankfort-Nachmias C. and Nachmias D. 1996 Research Methods in the Social Sciences (5:th ed.). London, New York. Arnold.

Garnsey, E. and Heffernan, P. 2005 Growth Setbacks in New Firms, Futures, 37; 675-697.

Gertler, M. 2003 Tacit knowledge and the economic geography of context, or the undefineble tacitness of being (there), Journal of Economic Geography, 3; 75-94.

Gibson C, Murphy P, Freestone R. 2002 Employment and socio-spatial relations in Australia's cultural economy, Australian Geographer, 33, 173-189.

Girard, M. and Stark, D. 2003 Heterarchies of value in Manhattan-based new media firms, Theory Culture and Society, 20; 77-105.

Goodman R. 1981 Temporary systems - professional development, manpower utilization, task effectiveness, and innovation, New York. Praeger Publishers.

Grabher, G. 2002 The project ecology of advertising: tasks, talents and teams, Regional Studies, 36, $254-262$.

Grabher, G. 2004 Learning in projects, remembering in networks: communality, sociality and connectivity in project ecologies, European Urban and Regional Studies, 11; 103-123.

Granovetter, M. 1985 Economic action and social structure: The problem of embeddedness American Journal of Sociology, 91; 481-510.

Izushi, H. and Aoyama, Y. 2006 Industry evolution and cross-sectoral skill transfers: a comparative analysis of the video game industry in Japan, the United States, and the United Kingdom Environment and Planning A, 38; 1843-1861.

Jack, S. Dodd, S. D. and Anderson, A. R. 2008 Change and the development of entrepreneurial networks over time: a processual perspective, Entrepreneurship and Regional Development, 20; 125-159.

Jacobs, J. 1969 The Economy of Cities, New York. Vintage Books.

Jansson, J. 2005 The Internet Industry in Central Stockholm - A Study of Agglomeration Economies, Social Network Relations, and Information Flows [Internetbranschen i Stockholms innerstad - En studie av agglomerationsfördelar, sociala nätverksrelationer och informationsflöden], Geografiska Regionstudier, No. 63. Uppsala University.

Jansson, J. 2008 Inside the internet industry - the Importance of proximity in accessing knowledge in the agglomeration of internet firms in Stockholm, European Planning Studies, 16; 211-228.

Julien, P-A, Endriambeloson, E. and Ramangalahy, C. 2004 Networks, weak signals and technological innovations among SMEs in the land-based transportation equipment sector Entrepreneurship and Regional Development, 16; 251-269.

Knight, Frank H. 1921/2006 Risk, uncertainty, and profit, Mineola N.Y. Dover Publications.

Lasch, F., Le Roy, F., and Yami, S. 2007 Critical growth factors of ICT start-ups, Management Decision, 45; 6275.

Leamer, E. and Storper, M. 2001 The economic geography of the internet age, Journal of International Business Studies; 32; 641-665.

Lundvall, B- A. 1992 National systems of innovation: towards a theory of innovation and interactive learning, London. Pinter.

Maksimovic, V. and Pichler, P. 2001 Technological innovation and initial public offerings, Rerview of Financial Studies, 14; 459-494.

Malecki, E. 2002 The economic geography of the internet's infrastructure, Economic Geography, 78; 399-424.

Marshall, Alfred 1890/1916 Principles of Economics: An introductory volume, London. Macmillan.

Maskell, Peter, Eskelinen, H. Hannibalsson, I. Malmberg, A and Vatne E. 1998 Competitiveness, localised learning and regional development - specialisation and prosperity in small open economies, London, New York. Routledge.

Maskell, P. and Malmberg, A. 1999 Localised Learning and Industrial Competitiveness, Cambridge Journal of Economics, 23; 167-185. 
McGahan, A. M. and Silverman, B. S. 2001 How does innovative activity change as industries mature? International Journal of Industrial Organization, 19; 1141-1160.

Morgan, K. 1997 The learning region: institutions, innovation and regional renewal, Regional Studies, 31; 491503.

Moriset, B. 2003 The New Economy in the city: emergence and location factors of internet-based companies in the metropolitan area of Lyon, France, Urban Studies, 40; 2165-2186.

Mugerauer, R. 2000 Milieu preferences among high-technology companies in Wheeler et al. Cities in the telecommunications age: the fracturing of geographies, New York, London. Routledge.

Murtha TP, Spencer JW, Lenway SA 1996 Moving targets: National industrial strategies and embedded innovation in the global flat panel display industry, Advances in Strategic Management, 13; 247-281.

National Post and Telecom Agency [http://www.pts.se/] 20021211.

Naylor, R. 1999 "Multimedia and uneven urban and regional development: the internet industry in the Netherlands in Braczyk et al. Multimedia and Regional Economic Restructuring, London, New York. Routledge.

Neff, G. 2005 The changing place of cultural production: the location of social networks in a digital media industry, Annals of the American Academy of Political and Social Sciences, 597; 134-152.

Newsweek, 7 februari 2000.

OECD 2002 Measuring the information economy, Organisation for Economic Co-operation and Development.

Patchell, J. 1999 Creating the Japanese electric vehicle industry: the challenges of uncertainty and cooperation, Environment and Planning A, 31; 997-1016.

Penfold, R. 2002 Risk, activity modularization, sourcing, and economic geography, Environment and Planning $A, 34 ; 1333-1353$.

Porter, Michael E. 1990 The Competitive Advantage of Nations, London. Mac-Millian Press ltd.

Power, D. and Hallencreutz, D. 2002 Profiting from creativity? The music industry in Stockholm, Sweden and Kingston, Jamaica, Environment and Planning A, 34; 1833-1854.

Pratt, A. 2006 Advertising and creativity, a governance approach: a case study of creative agencies in London, Environment and Planning A, 38; 1883-1899.

Rantisi, N. 2002 The competitive foundation of localized learning and innovation: the case of women's garment production in New York City, Economic Geography, 78; 441-462.

Sandberg, A. 1999 The multimedia Industry in Sweden and the Emerging Stockholm Cluster, in Braczyk et al. Multimedia and Regional Economic Restructuring. London, New York: Routledge.

Sawabe, N. and Egashira, S. 2007 The knowledge management strategy and the formation of innovative networks in emerging industries, Journal of Evolutionary Economics, 17; 277-298.

Schill, M.J. and Zhou, C.S. 2001 Pricing an emerging industry: evidence from internet subsidiary carve-outs, Financial Management, 30; 5-33.

Scott, A. 2001 Economic Geography: The great half-century in Clark et al. The Oxford Handbook of Economic Geography, Oxford. Oxford University Press.

Scott, A. 2006 Entrepreneurship, innovation and industrial development: geography and the creative field revisited, Small Business Economics, 26; 1-24.

Scott, S. and Walsham, G. 2005 Reconceptualising and managing reputation risk in the knowledge economy: toward reputable action, Organization Science, 16; 208-322.

Storper, M. 1995 The resurgence of regional economies, ten years later: the region as a nexus of untraded interdependencies, European Urban and Regional Studies, 2; 191-221.

Storper, M. and Venables, A. 2004 Buzz: face-to-face contacts and the urban economy, Journal of Economic Geography, 4; 351-370.

Strange, W., Hejazi, W. and Tang, J. 2006 The uncertain city: competitive instability, skills, innovation and the strategy of agglomeration, Journal of Urban Economics, 59; 331-351. 
Sydow, J. and Staber, U. 2002 The institutional embeddedness of project networks: the case of content production in German television, Regional Studies, 36; 215-227.

Tsoukas, H. and Hatch, M.J. 2001 Complex thinking, complex practice: the case for a narrative approach to organizational complexity, Human Relations, 54; 979-1013.

Watson, A. 2008 Global music city: knowledge and geographical proximity in London's recorded music industry, Area, 40; 12-23.

Winther, L. 2001 The spatial structure of the new economy in the Nordic countries, Nordregio, Working Paper 2001:10.

Wolf-Powers, L. 2001 Information technology and urban labor markets in the United States, International Journal of Urban and Regional Research, 25; 427-437.

Wolfe, D. and Gertler, M. 2004 Clusters from the inside and out: local dynamics and global linkages, Urban Studies, 41; 1071-1109.

Zafirovski, M. 1999 Probing into the social layers of entrepreneurship outlines of the sociology of enterprise. Entrepreneurship and Regional Development, 11; 351-372.

Zimmerman, M. A. and Zeitz, G.J. 2002 Beyond Survival: Achieving new venture growth by building legitimacy, Academy of Management Review, 27; 414-431.

Zook, M. 2000 The Web of Production: The economic geography of commercial internet content production in the United States, Environment and Planning A, 32; 411-426.

Zook, M. 2002 Grounded capital: venture financing and the geography of the internet industry, 1994-2000, Journal of Economic Geography, 2; 151-177. 